\title{
Removal of Saturated Monoglyceride in Biodiesel Using Adsorption and Its Effect on Low-Temperature Properties of Biodiesel Blends
}

\author{
Pheeraphak Srikwanjai ${ }^{1,2}$, Watcharin Ngampuengpis ${ }^{2}$, and Chawalit Ngamcharussrivichai ${ }^{3,4^{*}}$ \\ ${ }^{1}$ Program in Petrochemistry and Polymer Science, Chulalongkorn University, Bangkok 10330, Thailand \\ ${ }^{2}$ Petroleum Product and Alternative Fuel Technology Research Department, PTT Innovation Institute, Ayutthaya 13170, Thailand \\ ${ }^{3}$ Center of Excellence in Catalysis for Bioenergy and Renewable Chemicals (CBRC), Faculty of Science, Chulalongkorn University, \\ Bangkok 10330, Thailand \\ ${ }^{4}$ Center of Excellence on Petrochemical and Materials Technology (PETROMAT), Chulalongkorn University, Bangkok 10330, \\ Thailand
}

\begin{abstract}
Saturated monoglyceride (SMG) is a main cause of precipitate formed above cloud point of biodiesel (B100), which leads to filter plugging in diesel engine. In this work, we studied the effect of SMG content (0.1-0.7 wt\%) of palm biodiesel (PO-B100) on the cloud point (CP) of diesel fuels blended with PO-B100 at different concentrations (B0, B7, B10 and B20). Euro 4 and Euro 5 diesels with a high and low aromatic content were used, respectively. The effect of SMG concentration on CP of biodiesel blends was more pronounced in case of a low aromatic Euro 5 diesel. An extent of CP change was also affected by the initial SMG concentration of PO-B100 and biodiesel blending ratios since they determined the SMG content of the final biodiesel blends. An adsorptive removal of SMG in PO-B100 was investigated by using natural zeolite as much cheaper adsorbents than commercial magnesium silicate (MS) and silica gel. The crystalline structure of natural zeolite and MS was studied by X-ray diffraction. Both MS and silica gel exhibited higher performance than natural zeolite in the SMG removal at $45^{\circ} \mathrm{C}$. To improve the SMG adsorption capacity, the natural zeolite was treated with $1 \mathrm{M}$ nitric acid solution at $60^{\circ} \mathrm{C}$. The resulting modified zeolite had an increased $\mathrm{SiO}_{2}$ content, as measured by X-ray fluorescence spectroscopy, due to dealumination effect. Moreover, it showed an improved adsorption performance: the capacity of SMG adsorption was $31.5 \mathrm{mgsmG}^{-1}$, corresponding to a decrease of SMG content of PO-B100 from $0.7 \mathrm{wt} \%$ to $0.35 \mathrm{wt} \%$, when using $10 \mathrm{wt} \%$ adsorbent loading at $45^{\circ} \mathrm{C}$ for $50 \mathrm{~min}$. As a result, an increase in the cloud point of biodiesel blends was significantly retarded.
\end{abstract}

\section{Introduction}

Biodiesel (B100) is an alternative fuel produced via transesterification process in which triglycerides are reacted with methanol to yield fatty acid methyl esters (FAME). The B100 specification in Thailand is set at $\geq$ $96.5 \mathrm{wt} \%$ FAME, while the content of impurities as incomplete transesterified products, e.g. monoglycerides and diglycerides, was limited to $\leq 0.7 \mathrm{wt} \%$ and $0.2 \mathrm{wt} \%$, respectively. Monoglycerides can be classified into two groups based on type of fatty acids: saturated monoglycerides (SMG) and unsaturated monoglycerides (UMG). Only SMG was found as main component in the precipitate formed above cloud point (CP) of biodiesel, (Tang et al., 2008; Chupka et al., 2011; Plata et al., 2015), and leaded to filter plugging problem in diesel engine. SMG significantly increases CP of soy oil biodiesel (SO$\mathrm{B} 100)$ because less stable form alpha-phase convert to more stable form beta-phase that is less soluble in B100 for 10 times (Chupka et al., 2012). An increase in the concentration of SMG for $0.01 \mathrm{wt} \%$ in the SO-B100, biodiesel blend could enhance $\mathrm{CP}$ for $4{ }^{\circ} \mathrm{C}$ (Chupka et al., 2014). Palm oil biodiesel (PO-B100) is mainly used for production of biodiesel blends in Thailand. The Thai government policy encourages an increased ratio of biodiesel used in biodiesel blends from B7 to B20. However, to the best of our knowledge, there is no any research, which systematically studies the effect of SMG concentration on $\mathrm{CP}$ of biodiesel blends based on PO$\mathrm{B} 100$. In this work, we demonstrated the effect of SMG content $(0.1-0.7 \mathrm{wt} \%)$ of PO-B100 on CP of diesel fuels blended with PO-B100 at different concentrations (B0, $\mathrm{B} 7, \mathrm{~B} 10$ and $\mathrm{B} 20$ )

There are two low-energy consumed methods used for SMG removal from B100, so-called wet and dry process. The dry process removes SMG via adsorption, which reduces the amount of wastewater discharged and performs much faster, when compared to the wet process.

\footnotetext{
* Corresponding author: Chawalit.N@Chula.ac.th
} 
Commercial-grade magnesium silicate (MS) is a highly efficient solid material for adsorptive removal of SMG in $\mathrm{B} 100$, but it is expensive. There have been many researches devoted to development of cheaper adsorbents (Na-Ranong et al., 2015; Saengprachum et al., 2016). Increasing the silica and alumina content of adsorbents is an effective approach to increase the capacity of SMG removal in PO-B100. In this work, a natural aluminosilicate zeolite was used as an alternative adsorbent to reduce the SMG content of PO-B100. The major advantages of natural zeolite are much cheaper than MS and silica gel and tunable content of silica and alumina by a simple acid treatment (Wang et al., 2019).

\section{Materials and Methods}

\subsection{Chemical reagents and materials}

PO-B100, Euro 4 and Euro 5 diesel fuels (B0) with a high and low aromatic content, respectively, and SMG powder, consisting of monostearin and monopalmitin, commercial-grade MS and silica gel were provided by PTT Innovation Institute, Thailand. Natural zeolites with different particle sizes; bead natural zeolite (NZ-Bead), 200-mesh natural zeolite (NZ-200m), and 325-mesh natural zeolite (NZ-325m) were supplied from Pinpanat International Co., Ltd., Thailand.

Table 1 shows the composition and some important properties of PO-B100, while the properties and aromatic content of Euro 4 and Euro 5 diesels are shown in Table 2 . These as-received fuels were characterized by standard B100 and diesel specifications of Thailand. The PO-B100 samples with $0.1-0.7 \mathrm{wt} \% \mathrm{SMG}$ content were prepared by mixing the corresponding amount of SMG powder with PO-B100 at $60{ }^{\circ} \mathrm{C}$ under stirring. Subsequently, the POB100 with different SMG contents was mixed with Euro 4 and Euro 5 diesels to obtain biodiesel blends (B7, B10 and B20) for cloud point analysis.

Table 1. Properties of as-received PO-B100.

\begin{tabular}{lc}
\hline \multicolumn{1}{c}{ Properties } & Value \\
\hline Methyl ester (wt\%) & 99.3 \\
Linolenic methyl ester (wt \%) & 0.3 \\
Free glycerine (wt\%) & 0.005 \\
Monoglyceride $(\mathrm{wt} \%)$ & 0.05 \\
Saturated monoglyceride $(\mathrm{wt} \%)$ & 0.03 \\
Diglyceride & 0.01 \\
Triglyceride & 0.01 \\
Oxidation stability at $110^{\circ} \mathrm{C}(\mathrm{h})$ & 17.8 \\
Water content $(\mathrm{mg} / \mathrm{kg})$ & 553 \\
Total acid number $(\mathrm{mgKOH} / \mathrm{g})$ & 0.31 \\
Density @ $15.0{ }^{\circ} \mathrm{C}(\mathrm{g} / \mathrm{ml})$ & 0.8745 \\
Cloud point $\left({ }^{\circ} \mathrm{C}\right)$ & 14 \\
Cold filter plugging point $\left({ }^{\circ} \mathrm{C}\right)$ & 12 \\
Pour point $\left({ }^{\circ} \mathrm{C}\right)$ & 15 \\
\hline
\end{tabular}

Table 2. Properties of Euro standard diesel fuels.

\begin{tabular}{lcc}
\hline \multirow{2}{*}{ Properties } & \multicolumn{2}{c}{ Value } \\
\cline { 2 - 3 } & Euro 4 diesel & Euro 5 diesel \\
\hline Cloud point $\left({ }^{\circ} \mathrm{C}\right)$ & 6 & -2 \\
Cold filter plugging point $\left({ }^{\circ} \mathrm{C}\right)$ & 6 & -2 \\
Pour point $\left({ }^{\circ} \mathrm{C}\right)$ & 3 & -18 \\
Water content $(\mathrm{mg} / \mathrm{kg})$ & 62 & 58 \\
Mono-aromatics $(\mathrm{wt} \%)$ & 18.9 & 3.3 \\
Di-aromatics $(\mathrm{wt} \%)$ & 3.9 & 0.0 \\
Tri-aromatics $(\mathrm{wt} \%)$ & 0.3 & 0.0 \\
Total aromatics $(\mathrm{wt} \%)$ & 23.1 & 3.3 \\
\hline
\end{tabular}

\subsection{CP measurement}

The CP of PO-B100 and biodiesel blends were determined in accordance with ASTM D2500 standard test method.

\subsection{SMG analysis}

The SMG content of PO-B100 before and after adsorption was analyzed by gas chromatography. Typically, PO-B100 was weighed approximately $100 \mathrm{mg}$ (accuracy $\pm 0.1 \mathrm{mg}$ ) in a $10 \mathrm{~mL}$ vial. To this sample, 80 $\mu \mathrm{L}$ of $1,2,4$-butanetriol $(1 \mathrm{mg} / \mathrm{mL})$ and $200 \mu \mathrm{L}$ of standard glycerides stock solution $(2.5 \mathrm{mg} / \mathrm{mL})$ as internal standards were added. Then, $200 \mu \mathrm{L}$ of pyridine and 200 $\mu \mathrm{L}$ of $N$-Methyl- $N$-(trimethylsilyl)trifluoroacetamide were added. The vial was hermetically closed and shaken vigorously, followed by standing at room temperature for $15 \mathrm{~min}$, and adding $8 \mathrm{~mL}$ of $\mathrm{n}$-heptane. $1 \mu \mathrm{L}$ of the reaction mixture was used in the analysis using an Agilent Technologies $6890 \mathrm{~N}$ gas chromatograph equipped with flame ionization detector and a DB-5HT column.

\subsection{Acid treatment of natural zeolite}

To improve the SMG removal by natural zeolite, $1 \mathrm{M}$ nitric acid solution was prepared and mixed with the natural zeolite at an adsorbent: nitric acid mass ratio of $1: 10$. The temperature of acid treatment was investigated at room temperature and $60{ }^{\circ} \mathrm{C}$ for $1 \mathrm{~h}$. The treated natural zeolite was washed with deionized water several times until the solution became neutral, followed by filtration. Finally, the solid was dried at $120^{\circ} \mathrm{C}$ for $12 \mathrm{~h}$ and kept in a desiccator before being used for adsorptive removal of SMG from the PO-B100.

\subsection{Characterization of adsorbents}

The crystalline structure of adsorbents was characterized by X-ray diffraction (XRD) using a Bruker ADVANCE X-ray diffractometer. X-ray fluorescence spectroscopy (XRF) was used to determine the elemental composition of adsorbents before and after acid treatment. The morphological study was performed by electron probe micro analysis. 


\subsection{Adsorptive removal of SMG from PO-B100}

The adsorption performance of natural zeolites with different particle sizes in the SMG removal from POB100 containing the SMG amount of $0.7 \mathrm{wt} \%$ was compared with the commercial-grade MS and silica gel. In a typical batch, the adsorbents were dried at $120{ }^{\circ} \mathrm{C}$ for $12 \mathrm{~h}$ before being used. The adsorption was carried out at $45^{\circ} \mathrm{C}$ for $50 \mathrm{~min}$. The PO-B100 mixture was withdrawn and filtered through a syringe filter. The filtrate was then analyzed for the amount of SMG remaining using a gas chromatography.

\section{Result and Discussion}

\subsection{CP of biodiesel blends}

The relationship between the SMG content and CP of biodiesel blends (B7, B10 and B20) obtained by mixing PO-B100, consisting of different SMG content, with high aromatic (Euro 4) and low aromatic (Euro 5) diesels is shown in Figure 1. It reveals that increasing the SMG content of biodiesel blends increased CP significantly. The effect was more pronounced in case of a low aromatic diesel than Euro 4 diesel. The aromatic compounds might well dissolve SMG in diesel fuel (Chupka et al., 2014), and prevent the formation of SMG precipitate at low temperatures. An extent of $\mathrm{CP}$ change was also affected by the initial SMG concentration of PO-B100 and biodiesel blending ratios since they determined the SMG content of the final biodiesel blends. For B7, the critical SMG concentration at which $\mathrm{CP}$ increased sharply was $0.015 \mathrm{wt} \%$ (Figure 1(a)). When the SMG concentration of $\mathrm{B} 10$ was increased to $0.021 \mathrm{wt} \%$, CP was increased for 4 ${ }^{\circ} \mathrm{C}$ and $10{ }^{\circ} \mathrm{C}$ for the blends derived from Euro 4 and Euro 5 diesels, respectively (Figure 1(b)). A sharp increase in $\mathrm{CP}$ of B20 was observed at the SMG concentration in the range of $0.006-0.022 \mathrm{wt} \%$, during which $\mathrm{CP}$ was increased for $7-8{ }^{\circ} \mathrm{C}$ (Figure $1(\mathrm{c})$ ). The less effect of SMG content on $\mathrm{CP}$ of high-level biodiesel blends was explained by higher solubility of SMG in FAME than paraffic hydrocarbons (Chupka et al., 2014).

\subsection{Adsorptive removal of SMG from PO-B100}

The capacity of SMG adsorption onto different adsorbents is shown in Table 3. MS and silica gel exhibited much higher capacity than the natural zeolites. These materials could similarly adsorb the SMG molecules via hydrogen-bonding interaction (Saengprachum et al., 2016). A low adsorption capacity of natural zeolites should be related to their textural properties. Zeolites are microporous materials of which pore sizes inserted mass diffusion limitation in the SMG adsorption. Nevertheless, the natural zeolite is attractive in terms of much lower cost and tunable physicochemical properties. Herein, NZ-325m showed better SMG removal among the natural zeolites, and was selected for further study.
Table 3. Performance of different adsorbents in removal of SMG from the PO-B100 with $0.7 \mathrm{wt} \%$ SMG content.

\begin{tabular}{lcc}
\hline Adsorbent & $\begin{array}{c}\text { Adsorbent } \\
\text { loading } \mathbf{( w t} \%)\end{array}$ & $\begin{array}{c}\text { Adsorption capacity } \\
\text { (mg } \mathbf{m s G}_{\text {sMads }} / \mathbf{g}_{\mathbf{a d s}}\end{array}$ \\
\hline MS & 5 & 81.7 \\
Silica gel & 5 & 79.8 \\
NZ-Bead & 5 & 3.8 \\
NZ-200m & 5 & 15.2 \\
& 10 & 11.7 \\
NZ-325m & 5 & 22.8 \\
& 10 & 18.0 \\
\hline
\end{tabular}
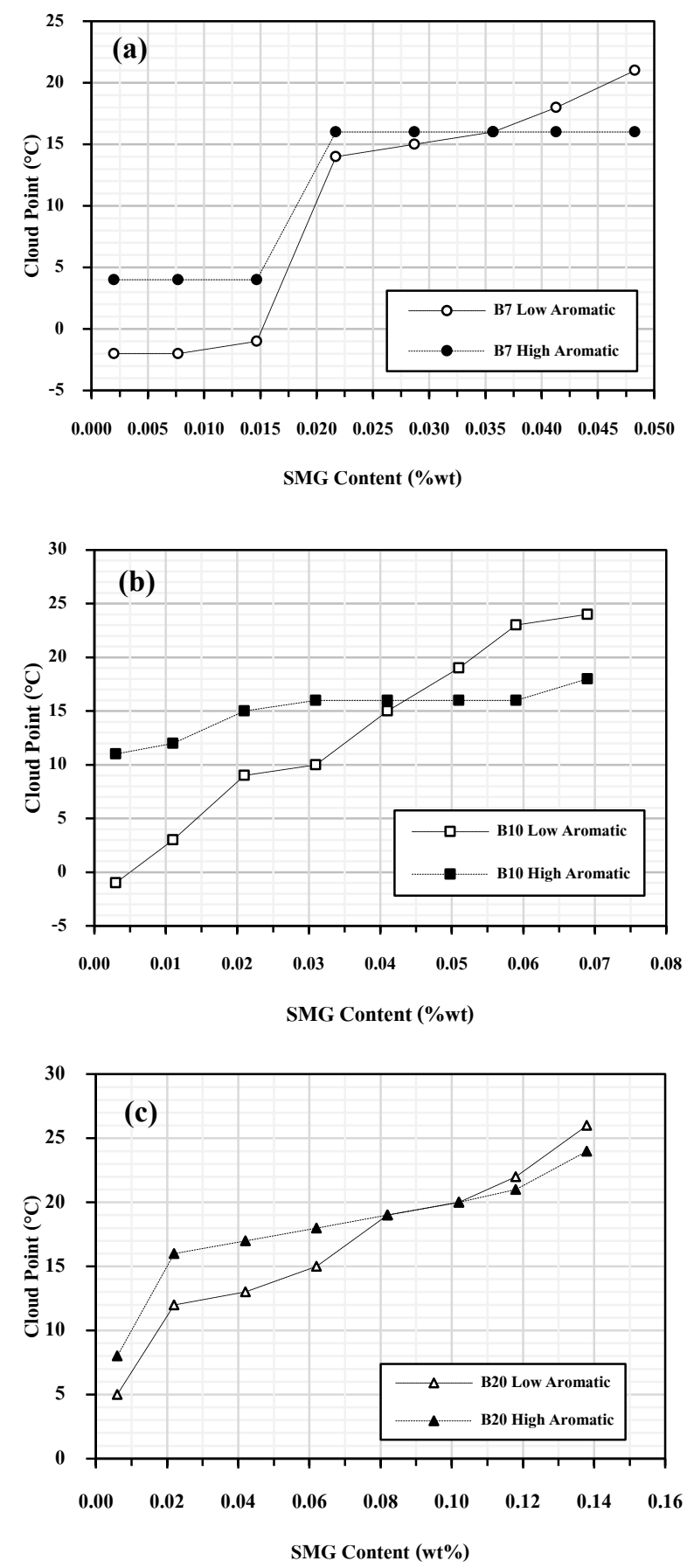

Figure 1. CP and SMG content of biodiesel blends: (a) B7, (b) B10 and (c) B20. 


\subsection{Properties of adsorbents}

The XRD patterns of different adsorbents are compared in Figure 2. It can be seen that MS exhibited magnesium silicate hydrate phase, corresponding to $2 \theta=$ $35.0^{\circ}$ and $60.5^{\circ}$, while silica gel was an amorphous material. The natural zeolites possessed mainly clinoptilolite phase. Clinoptilolite is the most common natural zeolite of heulandite family or structural variation of zeolite mineral group (Tran et al., 2019). It has large 12-membered ring pores with the effective pore size of 0.4 $\mathrm{nm}$ and a general chemical formula: $(\mathrm{Na}, \mathrm{K}, \mathrm{Ca})_{4}$ $\mathrm{Al}_{6} \mathrm{Si}_{30} \mathrm{O}_{72} .24 \mathrm{H}_{2} \mathrm{O}$ (Kussainova et al., 2019). Moreover, other phases (quartz, cristobalite, feldspar and sanidine) were found as impurities. There was no significant difference in the crystalline structure and elemental composition (Table 4) of NZ-200m and NZ-325m. The average particle size of NZ-Bead was 4-6 $\mathrm{mm}$. As shown in Figure 3, the MS particles were uniform spheres, while silica gel was irregular shape with particle sizes of 100$200 \mu \mathrm{m}$. NZ-200m had bigger particle sizes (ca. $71 \mu \mathrm{m}$ ) than NZ-325m (ca. $41 \mu \mathrm{m}$ ) due to grinding and sieving effect. The particle size of NZ-325m after the acid treatment was slightly decreased to ca. $34 \mu \mathrm{m}$, probably due to agitation effect.

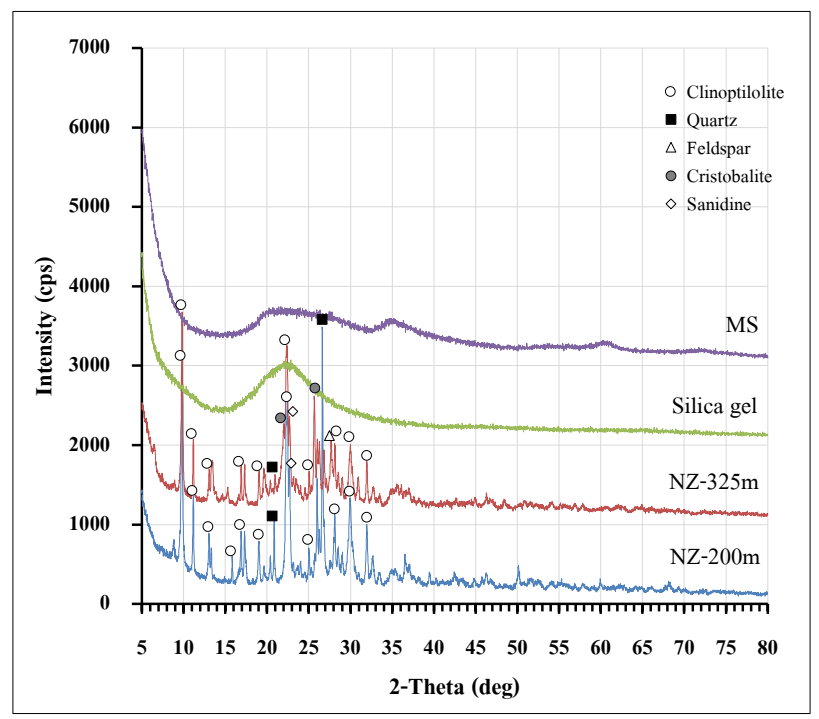

Figure 2. XRD patterns of adsorbent materials.

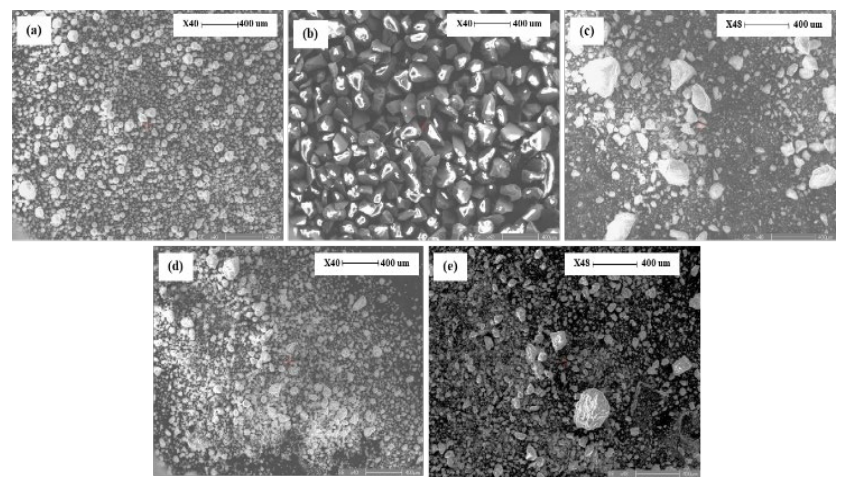

Figure 3. EPMA images of adsorbents: (a) commercial-grade MS, (b) silica gel, (c) NZ-200m, (d) NZ-325m and (e) NZ-325m treated @ $60{ }^{\circ} \mathrm{C}$
Table 4. Elemental composition of adsorbent materials.

\begin{tabular}{lcc}
\hline \multirow{2}{*}{ Adsorbent } & \multicolumn{2}{c}{ Elemental composition (wt\%) } \\
\cline { 2 - 3 } & $\mathbf{S i O}_{\mathbf{2}}$ & $\mathbf{A l}_{\mathbf{2}} \mathbf{O}_{\mathbf{3}}$ \\
\hline Silica gel & 98.8 & - \\
Commercial MS & 78.5 & 0.1 \\
NZ-200m & 75.1 & 13.3 \\
NZ-325m & 76.5 & 13.0 \\
NZ-325m treated @ RT & 78.5 & 12.3 \\
NZ-325m treated @ $60{ }^{\circ} \mathrm{C}$ & 79.4 & 11.9 \\
\hline
\end{tabular}

\subsection{Effect of acid treatment on SMG adsorption over NZ-325m}

As shown in Table 4, the content of $\mathrm{SiO}_{2}$ and $\mathrm{Al}_{2} \mathrm{O}_{3}$ in NZ-325m was decreased after the treatment with $1 \mathrm{M}$ nitric acid solution due to dealumination effect. The treatment at $60{ }^{\circ} \mathrm{C}$ slightly promoted the dealumination when compared to that at room temperature. Table 5 compares the adsorption capacity of NZ-325m before and after the acid treatment in the SMG removal from POB100 (0.7 wt $\%$ SMG). The result indicates that the acid treatment could improve the performance of NZ-325 $\mathrm{m}$ in the adsorption of SMG in PO-B100. Generally, the dealumination of zeolites not only generates defect sites as silanol groups but also enlarged pores, which can enhance diffusion and adsorption of SMG molecules (Wang et al., 2019). Another explanation was a reduced particle size of NZ-325m after the acid treatment, which provided higher contact area between the adsorbent surface and the liquid phase. The adsorption capacity of $\mathrm{NZ}-325 \mathrm{~m}$ treated at $60{ }^{\circ} \mathrm{C}$ was $32.6 \mathrm{mg}_{\mathrm{SMG}} / \mathrm{g}_{\text {ads }}$ at $5 \mathrm{wt} \%$ adsorbent loading. Using this acid-treated NZ-325m at 10 $\mathrm{wt} \%$ loading could reduce the SMG content of PO-B100 from $0.7 \mathrm{wt} \%$ to $0.35 \mathrm{wt} \%$. The content of free glycerin as an impurity after the adsorption using the acid-treated $\mathrm{NZ}-325 \mathrm{~m}$ was reduced to less than $0.005 \mathrm{wt} \%$. The resulting PO-B100 was used to prepare B7 biodiesel blend, followed by the $\mathrm{CP}$ measurement. The $\mathrm{CP}$ of $\mathrm{B} 7$ with a similar SMG content was supposed to be $16{ }^{\circ} \mathrm{C}$ (Figure 1(a)). However, it was dramatically reduced to 6 ${ }^{\circ} \mathrm{C}$, which was lower than expected. This result could be explained by the fact that the treated $325 \mathrm{~m}$ adsorbed not only SMG but also free glycerin, as a cause of $\mathrm{CP}$ increment.

Table 5. Performance of acid-treated NZ-325m samples in removal of SMG from the PO-B100 with $0.7 \mathrm{wt} \% \mathrm{SMG}$ content.

\begin{tabular}{|c|c|c|}
\hline Adsorbent & $\begin{array}{c}\text { Adsorbent } \\
\text { loading } \\
(w t \%)\end{array}$ & $\begin{array}{c}\text { Adsorption } \\
\text { capacity } \\
\left(\mathrm{mg}_{\mathrm{SMG}} / \mathrm{g}_{\text {ads }}\right)\end{array}$ \\
\hline NZ-325m & 5 & 22.8 \\
\hline NZ-325m treated@RT & 5 & 32.3 \\
\hline \multirow[t]{2}{*}{ NZ-325m treated @60 ${ }^{\circ} \mathrm{C}$} & 5 & 32.6 \\
\hline & 10 & 31.5 \\
\hline
\end{tabular}




\section{Conclusion}

The SMG content sharply influenced the $\mathrm{CP}$ of $\mathrm{B} 7$ : the critical SMG concentration was $0.015 \mathrm{wt} \%$. The effect of SMG concentration on $\mathrm{CP}$ of biodiesel blends was more pronounced in case of a low aromatic diesel (Euro 5) than Euro 4 diesel. The natural zeolite had much lower capacity of SMG adsorption than commercial-grade MS and silica gel, but the acid treatment using $1 \mathrm{M}$ nitric acid solution improved the performance of natural zeolite in the SMG removal from PO-B100. At $10 \mathrm{wt} \%$ adsorbent loading, the SMG content of PO-B100 was reduced from $0.7 \mathrm{wt} \%$ to $0.35 \mathrm{wt} \%$ and the resulting $\mathrm{B} 7$ biodiesel blend exhibited a reduced $\mathrm{CP}$ from $16{ }^{\circ} \mathrm{C}$ to $6{ }^{\circ} \mathrm{C}$.

\section{Acknowledgements}

The authors gratefully acknowledge PTT Innovation Institute, Thailand for support fuel materials and all facilities. This work is financially supported by the Thailand Research Fund (TRF) under the International Research Network: Functional Porous Materials for Catalysis and Adsorption (Contract No. IRN61W0003). The authors would like also to acknowledge the Center of Excellence on Petrochemical and Materials Technology (PETROMAT) and the Center of Excellence in Catalysis for Bioenergy and Renewable Chemicals (CBRC), Faculty of Science, Chulalongkorn University, Thailand for technical supports.

\section{References}

Chupka, G., J. Yanowitz, G. Chiu, T. Alleman, and R. McCormick; "Effect of Saturated Monoglyceride Polymorphism on Low-Temperature Performance of Biodiesel," Enegy Fuel, 25, 398-405 (2011)

Chupka, G., L. Fouts, and R. McCormick; "Effect of Low-Level Impurities on Low-Temperature Performance Properties of Biodiesel," Enegy Environ. Sci., 5, 8734-8742 (2012)

Chupka, G., L. Fouts, J. Lennon, T. Alleman, D. Daniels, and R. McCormick; "Saturated Monoglyceride Effects on Low-Temperature Performance of Biodiesel Blends," Fuel Process. Technol., 118, 302-309 (2014)

Kussainova, M., R. Chernyacova, U. Jussipbekov, and S. Pasa; "Structural Investigation of Raw Clinoptilolite Over the $\mathrm{Pb}^{2+}$ Adsorption Process from Phosphoric Acid," $J$. Mol. Struct., 1184, 49-58 (2019)

Na-Ranong, D., P. Laungthaleongpong, and S. Khambung; "Removal of Steryl Glucosides in Palm Oil Based Biodiesel Using Magnesium Silicate and Bleaching Earth," Fuel, 143, 229-235 (2015)

Plata, V., P. Gauthier-Maradei, and V. Kafarov; "Influence of Minor Components on Precipitate Formation and Filterability of Palm Oil Biodiesel," Fuel, 144, 130-136 (2015)

Saengprachum, N. and S. Pengprecha; "Preparation and Characterization of Aluminum Oxide Coated Extracted Silica from Rice Husk Ash for Monoglyceride Removal in Crude Biodiesel Production," J. Taiwan Inst. Chem. E, 58, 441-450 (2016)

Tang, H., R. Guzman, S. Salley, and K. Simon;
Soybean Oil Based Biodiesel Blends after Cold Soaking at $4^{\circ}$ C," J. Am. Oil Chem. Soc., 85, 1173-1182 (2008)

Tran, Y., J. Lee, P. Kumar, K. Kim, and S. Lee; "Natural Zeolite and Its Application in Concrete Composite Production," Compos. Part B-Eng., 165, 354-364 (2019)

Wang, C., S. Leng, H. Guo, L. Cao, and J. Huang;

"Acid and Alkali Treatments for Regulation of Hydrophilicity/Hydrophobicity of Natural Zeolite," Appl. Surf. Sci., 478, 319-326 (2019) 